\title{
El teatro de José Saramago por él mismo
}

\author{
María Josefa Postigo AldeAmiL \\ Departamento de Filología Románica, Fil. Eslava y Ling. General \\ Universidad Complutense de Madrid \\ portugal@filol.ucm.es
}

\section{RESUMEN}

Se reproducen en este artículo las palabras pronunciadas por el dramaturgo portugués José Saramago, Premio Nobel de Literatura en 1998, con motivo de una conferencia en la Facultad de Filología de la Universidad Complutense de Madrid en el mes de mayo de 1995. En esta intervención, Saramago habló sobre su producción teatral.

Palabras clave: José Saramago, literatura portuguesa, teatro

[Recibido, marzo 2011; aprobado, abril 2011]

José Saramago's theatre as seen by himself

\begin{abstract}
We transcribe, in this article, the words pronounced by the Portuguese author José Saramago, who was awarded in 1998 the Nobel Prize for Literature, in occasion of a lecture given at the Complutense University of Madrid in may 1995. During his speech, Saramago spoke about his theatre writings.
\end{abstract}

Keywords: José Saramago, Portuguese literature, theatre

Sobradamente divulgadas y estudiadas son las novelas de José Saramago, figura de excepcionales valores humanos y único Nobel de Literatura en lengua portuguesa, que falleció el 18 de junio de 2010. Menor atención y conocimiento por parte de expertos y estudiosos presentan sus textos dramáticos eclipsados por el brillo de su singular y sobresaliente prosa de ficción.

La primera vez que nuestra Facultad tuvo el honor de contar con la presencia del escritor portugués fue el 12 de mayo de 1995 en el Encuentro Hispano-Luso de Cultura, Literatura y Traducción. Y en 1996, al día siguiente del estreno en el Teatro Albéniz de su pieza $A$ Noite, representada en español, pronunció la conferencia que aquí transcribimos. Además, fuera de la Facultad de Filología, José Saramago tomó la palabra, en varias ocasiones en la Universidad Complutense: En la Facultad de Ciencias de la Información, en los Cursos de Verano de El Escorial, en el Foro Complutense. Meses después de su muerte, el 19 de noviembre 
Biblioteca Histórica Marqués de Valdecilla con el acto, José Saramago en sus palabras: mesa redonda, en el que participaron, entre otros, Pilar del Río y Fernando Gómez Aguilera con evocaciones emotivas y reflexivos pensamientos.

No es de extrañar que con estos antecedentes -gloria de las letras portuguesas y vinculado a la Complutense-, el área de Filología Portuguesa de esta Facultad quiera sumarse a los homenajes merecidos que desde diversos puntos del mundo se tributan a Saramago desde su muerte. Queremos rendirle homenaje transcribiendo la disertación, cuyo título él mismo escogió "El teatro de José Saramago por él mismo" pronunciada en el Paraninfo de nuestra Facultad de Filología de la Universidad Complutense de Madrid, el día seis de noviembre de 1996.

En la conferencia, destinada a un público estudiantil universitario, era la primera vez, según sus propias palabras, que hablaba de su teatro. No es fácil, ni pretendo, resumir en unas pocas líneas la trayectoria de los treinta últimos años en los que la dedicación de Saramago a la literatura, a las letras y al compromiso ha sido constante. Un modesto acercamiento a la literatura saramaguiana se puede encontrar en las páginas que escribí en 1996 con el título de "José Saramago: Da Literatura à Ética. (Uma aproximação ao livro Ensaio sobre a Cegueira)" y años más tarde (2001) en el artículo "José Saramago y los proverbios". En esos trabajos señalé las técnicas empleadas por el escritor en la elaboración de los diferentes textos destacando la novedosa manera de transmitir, mediante un estilo inconfundible y por medio de recursos perennes - la alegoría, el proverbio-, unos temas que preocupaban al hombre lúcido y comprometido. Las páginas que siguen provienen de la grabación de la conferencia y transcriben su intervención casi íntegra a excepción de unos minutos, al principio y al final de la misma, cuyo contenido nada tiene que ver con el tema a desarrollar y que por tanto no viene aquí al caso reproducir. En esta conferencia habla de su teatro, cuenta el comienzo de su inclinación por el mismo y analiza las cuatro obras teatrales que tenía escritas en ese momento, en 1996: A Noite (1979); Que farei com este livro? (1980); A Segunda vida de Francisco de Assis (1987); In Nomine Dei (1993). Son sesenta minutos en que el escritor, con inigualable elocuencia, predice con quince años de anticipación, muchos de los problemas candentes hoy en el mundo y que afligen al hombre real en 2011.

La transcripción de las cintas, guardadas durante años y que hoy se encuentran digitalizadas, ha sido laboriosa pero no difícil ya que José Saramago, como es conocido, logra una perfecta simbiosis entre el decir y el escribir. Confío en haber empleado adecuadamente los diferentes signos ortográficos para que esta conferencia sea perfectamente entendida en el medio escrito. Los lusitanismos y los que suponemos lapsus se señalan en cursiva y asterisco, y se aclaran en la última página ${ }^{\mathrm{i}}$.

Transcribimos a continuación las palabras de José Saramago: 
Bueno, ahora terminado este introito vamos al tema. Yo tengo que decir que esta es la primera vez que hablo en público de mi teatro. Entonces vosotros tenéis las primicias del abordaje o de la mirada que el autor tiene sobre una parte de su obra que es el teatro. La verdad es que si a mi se me pregunta qué usted hace en la vida, -si es que hace algo-. Yo digo: bueno, mire yo escribo, soy novelista. Pero la verdad es que no me ha ocurrido nunca decir que soy poeta, porque eso, aunque yo tenga libros de poesía, es algo que quedó casi en la prehistoria mía; tampoco diría que soy dramaturgo porque la verdad es que dramaturgo es el escritor que hace del teatro su expresión normal, escu$s o *$ tipo de comunicación artística, para decirlo así, con el público; lo hace continuadamente o con mucha más frecuencia. Y lo que me ha ocurrido a mí es que todas las obras de teatro que yo escribí hasta ahora han sido por encargo. Hay escritores a quien esta palabra encargo les causa una especie de erisipela; se sienten ofendidos en su libertad creadora. Bueno, hay que preguntarse qué es eso de la libertad creadora si uno vive en una sociedad determinada, histórica y culturalmente, que tiene sus gustos propios, sus tendencias, sus manías a veces, y de una forma $u$ otra igual que a nadie ocurriría hoy escribir o reescribir algo que se pareciese, por ejemplo, a Los Lusiadas o Lusíadas porque la sociedad no lo quiere, no lo requiere, no lo necesita; igual que eso, tampoco tendría algún sentido que en el siglo XIV o XV o XVIII un novelista hiciera algo de eso, por ejemplo, a que llamamos el realismo sucio. La libertad creadora es algo que uno tiene que defender pero está condicionada desde la raíz, condicionada por el hecho mismo de que uno vive en una sociedad determinada que tiene sus gustos; que le pide, aunque no sea inmediatamente, que le pide algo. Ahora, también esto tiene distintos niveles; puede que exista un escritor a quien nada preocupa más, a quien sólo preocupa saber que es lo que la sociedad pide y entonces está directamente al servicio... y eso, cantidad...;y para no hablar de la literatura podíamos hablar ahora de televisión y llegaríamos a la conclusión que la televisión está dando lo que, supuestamente, en este caso la sociedad le pide; lo que es, sabemos que es una mala señal, cuando nos damos cuenta que una parte importantísima, en cantidad, de la programación televisiva, en todo el mundo, no es más que basura y eso sería una señal complicada porque entonces llegaríamos a la conclusión que la sociedad quiere, pide, necesita, basura; lo que por otra parte quizá no esté muy alejado, no diré de la verdad, pero de alguna verdad.

Por lo tanto, cuando a mí me encargaron por cuatro veces, obras de teatro, a una persona que no tenía antes de la primera, claro, ninguna experiencia teatral, salvo la que puede adquirirse por el hecho de que uno se va al teatro o que alguna vez lee obras de teatro... Y yo me quedé así; y yo he dicho que no, que no, que no lo haría. La idea la tuvo, la primera vez, una directora de teatro que se llamaba Luzia Maria Martins, en Portugal, -entretanto ya no está en este mundo-, que se acercó, quizá en el año 78, por ahí, con la idea; y la idea era que yo escribiera una obra de teatro cuya acción o enredo, o lo que fuera, ocurriera en una redacción de un periódico. Ella, creo que me lo ha pedido por el hecho de que yo tenía alguna experiencia de periodismo, aunque una experiencia un poco particular porque yo no hice nunca una entrevista, ni un reportaje, ni una noticia. Estuve dos años, en el año 72 y 73 como editorialista en un vespertino que entonces existía que se llamaba Diário de Lisboa; por lo tanto, además de eso, coordinaba un suplemento cultural; y de ahí que es lo que ha pasado. Experiencia sí de cómo funciona un periódico, las idiosincrasias de la gente que trabaja en 
el periodismo, que por otra parte no son distintas de todas las de nosotros. Pero eso no me ha parecido a mí suficiente para que yo me atreviera a algo de que no tenía ninguna experiencia y le he dicho que no.

Pero como yo he dicho alguna vez el hombre y la mujer, -y sobre todo la mujer, si por la lección bíblica esa...-, nacemos nosotros para ser tentados; a veces nos tenta* una serpiente con una manzana en la mano, aunque yo no sé donde la serpiente tiene las manos, y a veces nos tenta* una persona que llega para decirnos: ¿y si tú hicieras una obra de teatro? Bueno lo que ha pasado ha sido esto. Yo he dicho que no, pero 24 horas después, o 48 horas después, estaba llamando a Luzia Maria Martins para decir: de acuerdo. Porque mientras, había tenido la idea. La idea era, que la redacción de un periódico, si señor, pero la noche, en la noche del 24 al 25 de abril de 1974. Esto ocurrió en el 78, algo por ahí. En el año 75 yo había estado como director adjunto del Diário de Notícias que era entonces el periódico más importante de Portugal, o por lo menos de Lisboa. Y ahí por tanto en 75, durante el tiempo más complicado de la Revolución Portuguesa, esa que vosotros llamáis de los claveles y que a nosotros, a mí personalmente, no me gusta nada que se diga de los claveles pero bueno, así son las cosas. Y ahí alguna experiencia más he ganado.

Y me senté a escribir pero a escribir qué ¿qué es lo que me importaba finalmente? En primer lugar, si esto ocurre en la redacción de un periódico en la noche del 24 al 25 de abril la revolución no está allí, la revolución está fuera; ni siquiera está fuera, porque a esa hora lo único que estaba ocurriendo es que tropas militares del ejército, todo eso, se estaban desplazando por las carreteras alrededor de Lisboa; y sí. Por lo tanto eso todavía no era una revolución; además ya hay que decir que la revolución portuguesa ha empezado después. La revolución en Portugal empezó, de hecho empezó, cuando el pueblo bajó a la calle. Es cierto que los militares derrumbaron el régimen podrido del fascismo portugués. Sí, eso es cierto. Es un dato histórico y hay que agradecerles pues; como hay que agradecer todo el trabajo político a ocultas, clandestino, a lo largo de casi cincuenta años, que la oposición portuguesa, de demócratas, de socialistas, de comunistas, incluso en alguna vez de anarquistas han hecho a lo largo de todo este tiempo. Pero se necesitaba el ejército y el ejército finalmente despertó; lo que ha hecho despertar el ejército en el fondo, ha sido, la guerra colonial; ha sido en África que los militares portugueses aprendieron la democracia, aprendieron que no podían seguir sirviendo al fascismo. Entonces lo que yo quiero decir es que la revolución propiamente dicha empezó cuando el pueblo bajó a la calle. Cuando empezaron las protestas, las reivindicaciones, las huelgas, todo eso ha sido una revolución social. Empieza por un golpe militar que después es fecundado, para decirlo así, por la intervención popular en el proceso. Entonces yo no podía hablar de la revolución a la hora en que todavía no existía revolución. Tampoco podía introducir militares porque estaban en los acuartelamientos o se estaban moviendo en los carros de combate.

¿Qué es lo que me interesaba finalmente? y eso es lo que sigue manteniendo la vigencia de una obra de teatro que ya lleva 17 años. En un tiempo en que todo, en que las modas cambian de una hora a la otra, en que todo lo que parecía bien ayer, hoy ya no se puede, ya no se aguanta, ya es tontería, ya es disparate. Como es que una obra, y yo tuve la prueba de eso ahora en Madrid y antes en Granada y en Motril....porque hemos representado La Noche en Motril. Cómo es que se llega a la conclusión y yo no es que crea, sé que algunos de los que están aquí estuvieron en el teatro Albéniz. 
¿Cómo es que 17 años después la obra sigue teniendo vigencia suficiente para emocionar a los espectadores, para hacerles sentir dentro, cosas que a lo mejor, que incluso creían olvidadas? Pues yo creo que la razón de eso, el motivo, es que ahí no se habla verdaderamente de revolución; se habla de la postura del periodista, y cuando digo del periodista digo del ciudadano en general, de a pie, en relación a lo que llamamos la libertad de prensa, el control de los medios que puede ser el control directo, -que hemos conocido nosotros y vosotros, aunque vosotros los que estáis aquí no, o casi nada-, de la censura directa, es decir de unos señores que se sentaban, a quien eran enviadas las galeradas de los artículos que se publicarían y que estaban allí para tachar, tachar: esto no, esto no. Yo me acuerdo que en Portugal un día y esto no es...y yo os doy este ejemplo, porque es ridículo, ridículo y al mismo tiempo trágico, una noticia que llevaba como título: Mañana, -o algo así- será el día internacional del niño. Como sabéis hay a lo largo del año cantidad de días internacionales: del niño, del sordo, del ciego, de la mujer; pero es muy divertido porque no hay un día internacional del hombre lo que muestra hasta que punto puede llegar la hipocresía de nuestra sociedad. Eso significa que el hombre ya no necesita nada, ya lo tiene todo pero a los ciegos, a los niños, a los viejecitos, a las mujeres hay que darles un día internacional para que las cosas cambien. El hombre no necesita nada; es decir la mujer no es un ser humano, es una mujer. Bueno, y esto, esta noticia tenía: Día internacional del niño. Y la censura tachó internacional. La mentalidad estrecha de esa gente llevaba a esto, que se borraban palabras tan terribles como esa: internacional. Si fuera hoy y todavía tuviéramos allí la censura, por ejemplo, una noticia que tuviera en el título o en el cuerpo de la noticia por ejemplo en una expresión como esta (que yo lo digo sin ninguna mala intención, ¿eh?): La internacional financiera. Pues no lo tacharían, no lo tacharían seguramente. Y eso... (estoy esperando vuestras sonrisas, ¿eh?) Bueno pues eso era la censura y entonces en eso estábamos y en eso vivíamos.

Entonces que es lo que me interesó más en esta obra. Conociendo como conocía, y bastante bien, lo que pasaba en la redacción de un periódico, en ese tiempo y sobre todo de un periódico como era, por ejemplo, Diário de Notícias que después se convirtió, en mi tiempo, en un periódico revolucionario, contra el cual todo el mundo estaba, con excepción de la clase obrera, y entonces no es que todos fueran conservadores o reaccionarios, estaban allí gente demócrata, gente que tenía otras ideas pero las tensiones estaban más o menos a lo largo de estos años y años y años, las tensiones estaban sofocadas, es decir, cada uno hacía lo que tenía que hacer y callaba o hablando bajito, con los que consideraba más cerca en el plano político o ideológico o lo que era... Y así es que hemos vivido. Llega la noche del 24 al 25 de abril y se imagina una redacción que está funcionando normalmente y que súbitamente llega la noticia: Hay tropas en la calle. Pero ¿para qué son las tropas? Bueno podrían ser de los estados capitanes de quien se hablaba tanto; podría ser un golpe de ultraderecha, - conocéis algo aquí de esto ¿no?; el Tejero ese que entra en las Cortes y dispara a lo bestia, tiros. Es decir es un espectáculo. Yo creo que todas las noches la televisión, las televisiones, deberían ofrecer a los españoles esos treinta segundos de imágenes para que nadie pudiera mañana decir: no, no lo sabía, son cosas que yo no me enteré. Porque la verdad que esto puede ocurrir, es algo que asombra. Ocurrió. Está bien que haya ocurrido para que se sepa que nada es seguro en esta vida ni nuestra propia vida personal ni la vida de las instituciones por muy democráticas que parezcan y por muy bien que parezcan fun- 
cionar. Llega esta noticia a esa redacción y ahí se desatan todas las tensiones; los compromisos con el régimen aparecen, la esperanza de los que se creen que algo hay que se puede cambiar, aparece.

Pero, yo no escribiría esta obra de teatro si no tuviera nada para decir, lo que parece una redundancia pero quizá no lo sea. Una obra de teatro por el hecho sencillo que puede escribir o intentaré escribir una obra de teatro no me parecía de recibo. Hay algo en el mundo que me ha preocupado siempre por lo menos cuando pienso en mí y me recuerdo a mí mismo, entre todas las cosas que yo he mantenido como preocupaciones vitales, casi vitales; esta es una de ellas: es el problema del poder. Nosotros nacimos, nos introducen en una sociedad constituida, organizada, funcionando; y lo recibimos todo, ¿cómo? con la misma naturalidad con que encontramos naranjas en los naranjos. Nos parece todo natural. Nos parece natural que haya presidente de la república o rey, que haya gobiernos, que haya parlamentos, todo esto nos parece natural. $\mathrm{Y}$, igual que no cuestionamos, igual que no insultamos el naranjo por el hecho de que no dé peras, también aceptamos que las cosas funcionen como funcionan, porque suponemos que no pueden funcionar de otra forma. Ahora tal como están las cosas y cada vez son más clarísimas, desde mi punto de vista por lo menos lo son. A veces me digo: pero usted no es muy demócrata ¿no? Y sí, sí lo soy, soy muy demócrata. Aunque tengo mala reputación, yo, la verdad es que lo que soy; lo que soy es demócrata de una democracia que no existe y si ella no existe la culpa no la tengo yo. Porque ¿como creéis que yo pueda creer en una democracia?... Y eso son todo temas que están en $\mathrm{La}$ Noche. Esto no es nada que yo estoy acrecentando para llevar el agua al molino mío, no. Son cosas que se habla en La Noche. Y si se habla allí es que en la realidad eso cuenta.

Ahora mismo, y yo hablo de esto porque la elección del presidente de Estados Unidos no es un evento nacional de ellos. No, es un evento mundial, nos interesa a todos y si no nos interesa no tenemos más remedio que interesarnos; porque los periódicos dan 4 páginas o 6 páginas de cómo iba vestido el Clinton, de cómo estaba peinado el doll. Y todo eso tenemos que saberlo como si fuera algo importante para nosotros y la verdad es que no lo es; o lo es de una otra forma y esa es la forma que a mí me importa más. ¿Quién gobierna el mundo? ¿Quién gobierna el mundo?

Pues nosotros que creemos en la democracia decimos pues quien gobierna el mundo son los gobiernos elegidos democráticamente por los ciudadanos, con sus parlamentos funcionando; hablo de los países donde la democracia existe, democracia de tipo occidental. Existe y está; son ellos, cada uno en su país y después se ponen todos de acuerdo unos con los otros. Pero yo me detengo a pensar en esto y me gustaría que si esto tiene algún interés que vosotros dedicarais un minuto o dos a lo largo de este día, o de mañana si no tenéis tiempo hoy, a pensarlo.

Es que nosotros que hablamos tanto de democracia no nos damos cuenta que el poder real de este mundo, el que gobierna, que es el sistema internacional financiero, no es democrático. No me he dado cuenta nunca de que en las elecciones portuguesas estén representados directamente los poderes financieros del mundo. Entonces a mí lo que me parece es que deberíamos revisarlo todo. Es decir, no podemos seguir hablando de democracia si quien gobierna el mundo no lo hemos elegido para gobernarnos. No hemos elegido a la financia* internacional para que nos gobierne, hemos elegido a gobiernos que salen, que resultan de la esencia de partidos, de la esencia de una Cons- 
titución; pero todo eso se queda ahí. Yo no quiero decir, no llevo tan lejos mis pequeñas manías, no quiero decir que los gobiernos no sean más que correas de transmisión o mandatarios o encargados de aplicar las políticas económicas y financieras que gobierna el mundo; pero lo que me parece ahí es que está fuera del control, ni siquiera indirecto, de los ciudadanos, ese poder. Cuanto mucho lo que podemos es quitar Felipe González y poner Aznar. Yo no tengo nada que ver con eso; yo no he votado. Eso sí; lo que no podemos es sustituir un financiero malo por un financiero bueno, si es que esa especie existe. La Noche habla de esto; porque ahí se plantea ¿pero de quien es la información? Eso que llamamos información, quién son los poderes que gobiernan la información, cuáles son sus objetivos, cómo es que se difunden las noticias, quien las difunde, por qué y para qué, qué cantidad de mentiras hay en eso que llamamos la información, quien las inventa, quien las distribuye, para qué, con que medios, con qué intenciones últimas? Y eso es lo que hace que La Noche tenga una vigencia. Es que yo no creo que...yo no soy más listo que nadie, a lo mejor soy mucho menos; lo que tengo es algo... tengo dos o tres ideas claras. Y una de ellas quizá en este momento de mi vida...el poder del señor Aznar en España o el poder del señor Chirac, ya estoy diciendo Chirac como si yo fuera castellano. Chirac, Chirac, Chirac. Chirac, Chirac no es nada; a él no le gustaría que yo le llamara monsieur Chirac. No, no, no, no son ellos; son ellos que salen en los periódicos, que aparecen en reuniones internacionales, que dan entrevistas a la televisión; son ellos. Pero los otros no aparecen en la televisión no dan entrevistas, no sabemos quienes son, no sabemos como se llaman. Entonces vamos a permitir, bueno no tenemos más remedio que permitir, claro, porque aquí no vamos a empezar una nueva revolución. Por eso me pregunto retóricamente vamos a permitir que nos sigan gobernando personas que no conocemos y cuyos intereses no coinciden con los nuestros.

Aquí me quedo. Esta es La Noche.

La segunda obra de teatro se llama cronológicamente...-todas ellas han sido representadas ¿eh?- No soy un autor inédito, en el escenario. Todas han sido representadas. La Noche tuvo en Portugal 120 funciones. La otra, un poco menos, pero bueno, no ha estado mal. La otra se llama La Segunda vida de Francisco de Assís. Daos cuenta que no es San Francisco de Assis, es La segunda vida de Francisco de Asís. Que es consecuencia... que aunque haya sido también una obra que me han pedido pero me han encargado, porque yo hablé de esto antes... del tema y entonces me dijeron ¿por qué no haces con eso una obra de teatro? Pues sí, entonces lo hago.

Un día en Italia, en ese pueblo magnífico que se llama Asís, visitando la iglesia y el monte donde se supone que... sí, no es donde se supone, donde es verdad, que San Francisco de Asís estuvo. Yo me encontré en el claustro con cuatro franciscanos, no eran cuatro eran tres, tres franciscanos. Así, como en una tienda, con sus hábitos de franciscanos marrón y vendiendo escapularios, crucifijos, estampitas y todo eso; crucifijos... todo allí; y yo que soy un ateo, confeso y declarado, que no creo en la existencia de Dios porque para eso me basta mirar el estado en que se encuentra este mundo porque si Dios nos creó para esto, entonces no ha valido la pena y, si no, habiéndonos creado para esto hemos nosotros llegado a esto; es que no necesitábamos de Dios para una creación, el diablo sería más que suficiente. Entonces yo me encontré allí; yo ateo y escrupuloso como todos los ateos somos, somos muy escrupulosos en esto de reli- 
gión ¿eh? Porque pensamos si vosotros sois creyentes entonces hacerme el favor de llevarlo muy en serio. Porque sino, no.

$\mathrm{Y}$ estaban los franciscanos, los de la pobreza, vendiendo estampitas, crucifijos, rosarios y todo eso. Esto me sentó fatal. Esto no puede ser. Yo lo he tomado como un insulto a San Francisco de Assís, un hombre bueno, bueno hasta donde alguien, un ser humano puede ser bueno; equivocado, a mi juicio, pero buenísimo. Entonces en Lisboa hablando de esto, expresé mi indignación de ateo hasta que un día también un director de teatro me preguntó y ¿por qué no lo pones todo en una obra? Y de ahí salió La Segunda vida de Francisco de Assis. Que se puede describir de esta forma. Imaginemos algo como que podemos llamar... una orden o empresa, o una empresa, o lo que sea, que tuvo en tiempos un fundador, que el tiempo pasó, el orden cambió- los cambios inevitables que vienen de las transformaciones sociales, económicas y todo eso. Y hasta que se creó una situación,- un poco de ciencia ficción si queréis o de política ficción si queréis, mejor, de ficción política- que el fundador, siglos después, vuelve a ver como están las cosas y se encuentra con los tres frailes franciscanos y vendiendo estampitas. Y, pero esto no era lo que yo creía...Entonces le explican: no, es que no, mira es que las cosas han cambiado mucho, ya no son como antes, ahora tenemos que seguir los tiempos, la corriente. No, esto no; es que hay un documento fundador que dice que nosotros no podemos tener bienes, que somos pobres, y que más; que hemos elegido la pobreza...

Mira que ahora he cambiado esto. Es que la segunda obra no es esta; es ¿Qué haré con este libro? Pero bueno tampoco eso es importante. Vamos a seguir con Francisco de Assís. Ahí se va a encontrar todo, es decir personajes con los mismos nombres de los que eran compañeros suyos, de San Francisco, en el siglo XIII: la madre, el padre, Clara que después ha sido Santa Clara; todo ese mundillo esta ahí. Y ¿qué es lo que intenta Francisco de Assis? Hacer volver a la empresa, si queréis llamar así, o a la orden, a lo que era antes; pero bueno se encuentra con los intereses constituidos, ¿por qué no? y además, el tiempo no vuelve atrás y no puede y no puede. Es el aparato mismo que está allí funcionando, que como sabemos es lo que tienen los aparatos, partidarios o partidistas, universitarios, que también los hay, que están ahí, que lo mantienen y lo dominan todo. Entonces el pobre Francisco se da cuenta que no; Francisco se llamaba... su nombre real era Juan. Cambió el nombre para Francesco por el hecho de que el padre de Juan que había hecho muy buenos negocios con Francia y, entonces, quiso que eso tuviera una... se reflejara en el nombre del hijo y le cambió el nombre para Francisco. Francia, Francisco, Francesco. Por donde van los intereses ¿no? hasta cambiar el nombre al pobre santo, el que todavía no lo era.

Entonces, como él no puede hacer volver lo que es a o que era, entonces intenta destruir lo que ha hecho; tampoco lo logra porque el aparato está ahí resistiendo y después tiene una idea que es esta: bueno la solución está ahí, yo voy a pedir a los pobres, que siguen existiendo, que me ayuden a destruir esto, porque esto es la corrupción total de la idea que yo tuve y si yo quiero seguir siendo pobre, nadie, nadie puede ayudarme más y mejor que los pobres; y se va a los pobres a pedir... bueno les cuenta, les narra lo que está pasando y les pide ahora vosotros venid conmigo a ayudar; y los pobres dicen que no, que no, porque hay una diferencia entre querer Francisco de Asís ser pobre, dejar de ser rico para ser pobre, hay una diferencia entre eso y el hecho de que uno es pobre porque es pobre. Y le dicen: nosotros no tenemos nada que ver con- 
tigo, nosotros no hemos elegido la pobreza pero tú, sí la has elegido; entonces es un problema tuyo, no es un problema nuestro. Y San Francisco de Asís, por eso yo decía que, aunque equivocado, se da cuenta de que lo malo es la pobreza, que la pobreza no es santa y entonces vuelve la espalda a la orden que había fundado; cambia, recupera su nombre de Juan y se va a vivir, a luchar contra la pobreza. Y esta es La Segunda vida de Francisco de Asís.

A esta hora vosotros estaréis pensando: bueno que señor este que en todo lo que hace mete política; es que no se aguanta, esto ahora no se usa. Pues no, pero mire ya no tenéis mucho tiempo para que yo siga metiendo política en todo porque como dentro de dos semanas cumplo 74 años no me queda mucho más y entonces, a partir de ahí, ya no tendréis que escucharme meter política en todo; pero mientras viva, lo haré.

La segunda obra, de que voy a hablar es Que farei com este livro? Una vez más un encargo. Se conmemoraba en el 82 el centenario de la muerte de Camões. Y entonces... 80, 82, 80 no, sí 82. Y entonces... Por qué no haces tú una... -la misma compañía que ha montado La Noche; por otra parte no ha sido Luzia Maria Martins por otros motivos, por motivos que no vienen al caso-, hacer una cosa sobre Camões y todo. ¡Hum!...Pues sí. Y ¿qué es lo que yo he hecho? Y una vez más, aunque todo esto ocurra en el siglo XVI, la política tampoco estaba ausente. Porque ahí, ahí vamos a tener todo. Es decir, es una obra irrepresentable, irrepresentable hoy porque ahora lo que se quiere en el teatro son dos o tres personajes, no más, que digan cosas muy graciosas, muy divertidas; si, pues, en un momento determinado, de una punta del escenario a la otra pasa, corriendo o no, una chica más o menos desnuda, mejor. Pero en esta obra no, son señores muy importantes es el rey D. Sebastián de Portugal, es el cardenal D. Enrique, entonces estaba como regente, es D. Catarina, española, la abuela de D. Sebastián. Y hay por ahí nobles, hidalgos, cortesanos, gente del pueblo y Luís de Camões y sus amigos Damião de Goís, Diogo do Couto. Desde luego es un tiempo verdaderamente extraordinario aunque uno muchas veces sólo se da cuenta de lo extraordinario que los tiempos han sido cuando los podemos mirar un siglo o dos siglos después: por eso es que llamamos, llamáis hoy vosotros, Siglo de Oro, a lo que entonces no lo era, porque en el Siglo de Oro nadie estaba diciendo: estamos viviendo en el Siglo de Oro.

¿Y, qué Camões es este mío? No es el conquistador, el que estuvo en Ceuta y se fue a la guerra, y que estuvo...; no es el seductor de quien se habla que seducía a todas las mujeres, una especie de don Juan; no es el seductor y guapo y rubio, con una facundia increíble. No es eso, no señor. Es un hombre que llega, vuelve de India con su manuscrito, Os Lusíadas, bajo el brazo, y que sencillamente anda buscando un editor, nada más. Es que el épico, el maravilloso poeta que es Camões que siglos después leemos así en las páginas de una edición muy bonita, o de una edición sencilla, popular y que decimos que bonito es esto, que bien lo que está diciendo. ¿Qué poeta es este? Pues este señor tuvo sus problemas, enfermedades, angustias, lloró, rió seguramente algunas veces, tuvo amores, unos buenos, otros desgraciados, y llega de India con su libro buscando un editor. Está enfermo; es un hombre que tiene cincuenta y pocos años pero a esas alturas un hombre con cincuenta años ya era un hombre mayor. Y que se encuentra con una corte a quien le da igual eso de que él tenga una cosa que se llama Lusíadas, qué les importa eso, qué les importa eso; entonces eso son las humillaciones. Cuando un autor hoy, que no es Camões, tiene su librillo y anda por ahí 
buscando un editor y le dicen que no y eso es una humillación porque cada uno de nosotros cree que su obra es magnífica y que si no es magnífica por lo menos merece que alguien le dé atención y que lo publique y sobre todo que lo publique y que la crítica después hable de ella y que diga en fin...y que tenga lectores.

Todo eso es humano y todo eso lo queremos pero tenemos que pensar que eso ocurrió también en el siglo XVI. Ocurrió un poco más tarde a Cervantes. Ocurrió todo eso en gente que hace, que busca después la forma de que eso llegue al público y que muchas veces no encuentra sino incomprensión, desprecio, humillación y todo eso. Y esto es la historia que yo cuento de Camões. No es una obra grandilocuente, retórica, de pompa, no. La pompa si que existe, en el paço, en el palacio, en la gente. Pero quien anda por allí, mendigando como quien ha pedido una limosna, es un señor llamado Luís Vaz de Camões, no es Luís Vaz de Camões es Luís Vaz de Camões que anda pidiendo, por favor que quiere hablar con el rey. Hay un cuadro, una pintura del siglo XIX, bien intencionada, que muestra Camões leyendo Os Lusíadas al rey D. Sebastião en el paço de Sintra- creo que en Sintra-. Es una pintura, como esas pinturas, todas esas pintura que se hacen, aúlicas, es decir de homenaje y todo, que quiere engrandecer la figura del poeta, claro; que quiere encontrar en el rey el sentimiento de receptividad suficiente para que oiga a un poeta; pero que a lo mejor no ocurrió. En esta obra de teatro ¿Qué haré con este libro? el rey no contesta es decir Luís de Camões se presenta: Ahí está señor, esta es mi obra; y él pasa, no lo mira siquiera, no lo mira siquiera, y entonces él...la frase última de la obra es esta: ¿Qué haréis con este libro?; mejor, él se pregunta a si mismo, Qué haré, yo, autor, qué haré con este libro; pero después se vuelve adonde está el público, en el patio de butacas y le pregunta directamente ¿Qué haréis vosotros con este libro?

$\mathrm{Y}$ esto es lo que nos están preguntando todos los días, a todas las horas, no sólo los autores muertos, pero también los vivos; ni no sólo los escritores, nos lo están preguntando los músicos, los pintores, nos lo están preguntando los filósofos, nos lo está preguntando la gente que busca pensar lo que es ser un ser humano y que a toda hora, hace esa pregunta ¿qué haréis vosotros con esto que yo he pensado, he escrito, he pintado, he compuesto? Y aquí está.

La última, -y afortunadamente que yo no soy un dramaturgo- porque entonces yo no tendría cuatro obras de teatro, tendría cuarenta y este encuentro nuestro no acabaría más o acabaría cuando vosotros, poquito a poquito, poquito a poco saliendo discretamente hasta que me encontrara con las sillas desocupadas y ahí se quedaría la obra. La última obra, que no sé si habrá otra en el futuro, pero esta es la última, se llama In Nomine Dei. Como sabéis significa En Nombre de Dios. Es otra manía mía esta de preocuparme mucho con Dios, este Dios en que yo no creo pero yo sigo diciendo que si otras personas, otros, creen en Dios, entonces Dios existe para mí en esas personas. No es que el hecho de que exista en esas personas sea suficiente para que yo crea pero si, igual que tengo que creer en la palabra de una persona que me está diciendo: Mañana...ayer llovió; es decir la lluvia de ayer para mí es una realidad, si yo creo en que la persona no me está engañando. Y si esta misma persona dice, Yo creo en Dios, entonces yo tengo que decir este señor cree en Dios. Por lo tanto Dios pasa a existir para mí en él. Esto me lleva a que más o menos la religión y sobre todo el cristianismo, y sobre todo el catolicismo, siempre aparece más ya lo habéis visto en La segunda vida de Fancisco de Assís en El Evangelio según Jesucristo, una novela mía, y a lo largo 
de todas las otras novelas mías siempre es de Dios. Dios como poder, Dios como instrumento, no sé si voluntario o involuntario de un poder instituido que es la iglesia; eso me interesa mucho igual que me interesa el otro poder del que hemos hablado antes, el poder financiero internacional porque la verdad es que Dios es una especie de poder ideológico internacional.

Eso explica que el tema me siga interesando mucho y en Ensayo sobre la Ceguera cuando al final de la obra dos de mis personajes con el perro al que yo llamo el perro de las lágrimas porque es un perro que anda por ahí. Todo el mundo está ciego los que han leído aquí, alguno que haya leído y si no lo han leído que lo lean, vamos, porque la obra no es mala. Todo el mundo se queda ciego. No se crean que no tiene explicación; que es una metáfora de la ceguera de nuestra razón. Mi pregunta es esta: si es verdad que somos seres racionales. Yo creo que no; el hecho de que yo esté haciendo aquí un uso regular, regular, normal de la palabra, que yo esté organizando un discurso, con algunas ideas que por lo menos encajan unas en las otras, eso no significa, no es suficiente para yo diga que soy racional porque lo que cuenta no es lo que uno dice lo que cuenta verdaderamente es lo que uno hace. Y si es verdad que de discursos bonitos y bien organizados estamos bien todos los días; los recibimos, los leemos y los escuchamos; de comportamientos racionales no creo que eso ocurra. Y no necesito ahora describir el estado del mundo, de nuestros países, el mío o el vuestro, para que se pueda llegar a la conclusión fácil que de racionalidad hay muy poca. El Ensayo sobre la Ceguera es eso, es una reflexión, es una novela pero de todas formas es una reflexión sobre eso, sobre la razón humana o la ausencia de la razón en los comportamientos humanos. Entonces al final hay un momento en que dos de los personajes con ese perro de las lágrimas, que es perro de las lágrimas porque se compadece, tiene compasión de una mujer que está llorando y se acerca a ella y le lame la cara para recibir las lágrimas. No sé quien ha dicho un día que nosotros deberíamos agradecer a los perros el hecho de que un día, no sé cuando, hayan decidido vivir con los humanos. No sé si esto no es más que una frase bonita, o si hay algo de verdad, pero a mí me ha gustado que la persona que se apiadara, que tuviera compasión, la persona, daos cuenta que yo he dicho la persona, que se acerca a la mujer que está llorando sea un perro y por esto le llamo después el perro de las lágrimas. Esos dos personajes, con el perro de las lágrimas, entran en una iglesia; ella no está ciega pero todos los demás sí, y entonces ella se da cuenta de algo increíble; hay una cantidad de personas, ciegos todos ellos que se refugiaron en la iglesia, y ella se da cuenta de que todas las imágenes sacras, desde Cristo hasta el santo más desconocido o menos conocido, todos tienen los ojos tapados. Que alguien ha tapado con la venda a las estatuas, que ha pasado con la brocha blanca sobre los ojos de las imágenes pintadas y esto por una razón muy sencilla es que si nosotros estamos ciegos todos, entonces Dios y sus santos no merecen vernos. Esto es algo muy fuerte yo diría incluso que es una blasfemia pero hay que decir las cosas como a uno le parecen que son.

Y esto como yo estaba diciendo antes, es un caso más en que la religión ha entrado y no me negaré para volver a esa obra, también resulta de un encargo lo que yo llamo el encargo social la sociedad pide al escritor o al pintor o al músico o a quien sea, Hazme esto y el músico, el pintor o el escritor decide lo hago o no lo hago. ¿Qué es lo que me ha pedido esta entidad? Esta entidad es la ciudad alemana de Münster. Münster está en el norte. Münster significa monasterio. Y no es que yo sepa alemán, 
tranquilos; me informé; pero de todas formas esto resulta bien hoy: que Münster significa monasterio. Y quien me oye decía: Lo que sabe este señor; pues no sabe tanto cuanto... lo que sí sabe es hacer buen uso de lo poco que sabe. Y entonces qué es lo que pasaba. La ciudad ha sido fundada por Carlomagno hace mil doscientos años y ¿qué era lo que pretendía la ciudad? Conmemorar el hecho, ese evento, esa efemérides, esa fecha, con algo así importante. Y ocurrió.

Recordar que en el siglo XVI en la misma ciudad de Münster y en toda esa región hubo después de la reforma de Lutero, hubo, en fin, lo que llamaban, se llamó entonces, se llama y se sigue llamando guerras de religión; que en este caso no era entre musulmanes o mahometanos y cristianos pero sí entre cristianos y cristianos. La ciudad de Münster tuvo la particularidad de ser un lugar donde una -yo no quiero llamar secta-porque eso sería despreciarla o por lo menos menospreciarla- lo que se llamaba los anabaptistas. Los anabaptistas, entre otros motivos, entendían... entre otros motivos que los llevaban a no querer tener nada que ver con el Vaticano, con el Papa, era que el bautismo no podría ser cosa de que en los primeros días del nacimiento del niño, que no, que el bautismo debería ser pedido cuando el niño llegara a la edad de la consciencia, decir yo quiero ser bautizado. Entonces rechazaban eso de que el bautismo tiene que prácticamente ser inmediato, después del nacimiento. No, que tenía que esperar hasta la edad de la consciencia para después pensar, opinar y decir: quiero el bautismo. Los católicos, claro, no estaban de acuerdo con esto. Había otras diferencias más de orden teológica más sutil y ahí se enfrentaron todos ellos en una guerra tremenda que en el caso de Münster que era una ciudad que tenía 12.000 habitantes, una pequeña... un pueblo, pero como en ese tiempo, en el siglo XVI, claro...; y que al cabo de un cerco de catorce o diez y seis meses con los anabaptistas dentro y los católicos cercando la ciudad, acabó con dos mil personas y las otras han sido degolladas torturadas, quemadas; ha sido una carnicería.

Y esto pareció a Münster que estaba bien, que se conmemorara, que se recordara; y la idea era que se compusiera una ópera sobre este tema y ¿qué es lo que me pedían a mí? Entonces nos reunimos, allí en Münster, el director del teatro de Ópera, el compositor que además había hecho...que es Azio Corghi, un compositor italiano que hizo la música para una otra ópera llamada Blimunda que ha sido extraída de Memorial del Convento y por lo tanto era la segunda vez que íbamos a colaborar uno y otro, juntos; y entonces yo pregunté pero vosotros no tenéis aquí en Alemania escritores para hacerlo, porqué me estáis pidiendo esto. No, es porque pensamos que tu eres la persona que en estos temas interesa mucho y no hay mucha gente ahora en Europa ni aquí que lo haga. Bueno de acuerdo lo intentaré, más una vez lo intentaré. Y lo intenté y la obra existe y la ópera se ha representado ya en Münster, en Ferrara, en Italia. Será representada ahora en principios de enero en Catania, en Sicilia e irá por ahí, en Ámsterdam y no sé donde más.

Y es una obra la mía, y la ópera que se hecho después, sobre la intolerancia, sobre la intolerancia. Porque aquí hay algo que una vez más me da la razón cuando yo digo que no somos seres racionales; es decir, que uno se enfrente con otra persona por el hecho de que él cree en Alá y yo creo en lo que llamamos el Dios de los cristianos; bueno, son diferencias que tienen que ver con la concepción de vida de cada uno de ellos y por lo tanto puede llevar a incompatibilidad y todo eso. Y aunque yo no entienda, que en nombre de alguien que no está presente, que es Dios, se mate, se tortu- 
re o se degüelle o todo eso, bueno, puedo aceptarlo porque la realidad está ahí y por lo tanto no tengo más remedio... porque uno cree en Alá y otro cree en Dios, en el Dios nuestro o vuestro; pero ahora...porque uno se presenta con el Corán y otro se presenta con la Biblia- y ni siquiera se presenta con la Biblia, se presenta con el Nuevo Testamento que es otra cosa. Pero ahora, que dentro de la misma religión, creyendo en el mismo Dios católicos y protestantes, en este caso en la versión anabaptista, se enfrentaran unos contra otros con una crueldad que no tiene nombre eso es algo a lo que yo no llego. Todos mis esfuerzos para comprender esto no me llevan a entender nada. Porque...y además yo os pido que os deis cuenta de esto: Es que esta guerra, una guerra religiosa de este tipo, entre creyentes en el mismo Dios presentará a Dios un problema muy complicado; porque el problema aquí es que este señor estaba en guerra para llegar al mismo paraíso- porque no hay un paraíso para los protestantes y un paraíso distinto para los católicos; habrá un paraíso para los cristianos o un infierno o un purgatorio, aunque ahora hay dudas sobre la existencia real del purgatorio. Es que en el día del Juicio Final, si seguimos creyendo en eso, se van a presentar delante de Dios los católicos de Münster y los anabaptistas de Münster; y qué hace Dios. Si recibe a los católicos y dice: vosotros protestantes al infierno. No, porque ellos creen en ese Dios. Si al contrario, dice a los protestantes: al paraíso, y vosotros católicos al infierno; los católicos dicen no, Como es que podemos ir al infierno si creemos en ti. Entonces Dios no va a tener más remedio que recibirlos a todos en su paraíso; lo que demuestra que la guerra, esa, ha sido inútil; ha sido un atentado a la razón.

Bueno, la intolerancia es algo que nosotros creíamos que después de la Segunda Guerra Mundial y de todos esos horrores y de algunas cosas más que ocurrieron, que estaría.... que sería una cosa más o menos...bueno que no estaría banida* del mundo pero que estaba controlada por ahí. Se necesita ser muy ingenuo; se necesitaba ser muy ingenuo para creerlo; pero la verdad es que nosotros tenemos tanta esperanza, o mejor, tenemos tanta necesidad de esperanza que incluso creemos en cosas que no están muy claras y esa era una de ellas. Cómo es que milenios de intolerancia, de muerte, de violencia, de estorsión, de tortura,- que ha sido lo que ha hecho el hombre al hombre a lo largo de todo este tiempo; de un momento a otro se iba a convertir en algo, por lo menos más sensato.

Pues no, la intolerancia está ahí, otra vez; siempre estuvo pero está ahí otra vez. Entonces esta obra que es sobre algo- igual que La Noche que diez y siete años después uno se preguntará qué vigencia tiene y parece que la tiene toda-, una obra sobre algo que ocurrió en el siglo XVI, por lo tanto hace cuatrocientos cincuenta años, porque esto ocurrió en 1530, 31, 32, 33, algo así, pues sigue teniendo toda la vigencia del mundo. Pero yo aprovecharía para llamar vuestra atención para un dato que, por lo menos en mi opinión, me parece importante. Nosotros, normalmente decimos que lo que se opone a la intolerancia es la tolerancia y eso me parece por lo menos insuficiente; porque no hay nada que esté más cerca de la intolerancia que la tolerancia. Según las circunstancias, según los motivos, según los momentos. Y les voy a dar un ejemplo: Imaginemos un país,- y no es difícil imaginar porque está ahí; Francia por ejemplo, Luxemburgo, Alemania-, que en un momento determinado de su historia por una crisis, necesita mano de obra de fuera, extranjeros; pues reciben a los emigrantes, los tratan bien, incluso los ilegales; las cosas se arreglan y en los países de origen decimos muy contentos, Nuestros emigrantes son muy buenos. Porque los emigrantes tie- 
nen una cosa extraordinaria es que parece... parece, que trabajan más en el exterior que en su propio país. Y por eso nosotros- que somos un poquito tontos,- nos quedamos muy orgullosos de nuestros emigrantes; porque los extranjeros, los de fuera nos dicen Ay que buenos, sensatos, trabajadores, discretos; que no piden nada; que se satisfacen con lo que hay, con lo que tienen, Que buena gente; y es como si les estuvieran justificando nuestra propia existencia en el mundo; pero cuando la economía de esos países mejora y la mano de obra de fuera ya no es necesaria, entonces los emigrantes, hasta entonces tolerados -y ahí entra la palabra-, hasta entonces tolerados, se vuelven, muy prontamente, intolerables y entonces tenemos leyes que dificultan, que introducen dificultades de todo el orden para que la gente se mantenga; les hacen volver al país de origen y todo eso.

Entonces cuando yo digo que cuidado con la tolerancia porque la tolerancia no es más que esto: yo tolero, yo tolero la existencia del otro; pero quien soy yo para tolerar la existencia del otro; como es que yo me permito decir que tolero la existencia del otro, sea quien sea. El otro, desde el punto de vista nuestro, es siempre o el marginal, o el de otro país, o el de otro color o el de otra religión o raza; el otro lo que llega de fuera, la amenaza que llega de fuera. Yo puedo decir,- porque yo soy muy buenoBueno yo no tengo nada contra ellos, los tolero. Pero quien soy yo para decir que yo los tolero y ¿por qué no dicen ellos que me toleran a mí? La verdad es que ahora mismo, de esto todos vosotros sabéis esa gente que viene en las pateras y que busca trabajo y pan fuera del país que está ahí, de Marruecos y de todo eso. Qué es lo que hacemos-, o qué es lo que hacéis porque, como en nuestras playas no desembarcan, no tenemos ese problema-, pues los devolvemos a la procedencia. Bueno ya no está mal porque no los hundimos a cañonazos pero los volvemos a la procedencia. Pero paremos un poquito a pensar qué es lo que habría ocurrido si los africanos o los pieles rojas o los indios en general nos hubieran devuelto a la procedencia cuando hemos llegado a África o a India o a América o todo eso. Es que a lo mejor no estaría mal que nos hubieran devuelto a la procedencia. De todas formas estamos...,-no sé si es una especie de destino o si es una necesidad-tenemos que vivir unos con los otros; eso está clarísimo. Lo que hemos hecho hasta ahora ha sido más bien vivir unos contra los otros. Cómo es que podemos llegar a vivir los unos con los otros eso yo no lo sé. No soy más que un escritor que en este caso no hablo más que de obras de teatro, que afortunadamente, repito, no ha escrito más que cuatro; si de novela se tratara entonces estaríamos todavía hablando aquí hasta no sé cuando pero quizá pueda quedar para otra vez.

Yo quiero terminar agradeciendo la presencia del Embajador de Portugal, del Consejero Cultural. Que está muy bien. Es algo que a nosotros los que andamos por el mundo y que escribimos - que las cosas son así ahora- y tenemos que hablar de las cosas que hemos hecho. No quiero decir siempre pero, una vez u otra, la presencia de quien representa al país es algo muy reconfortante. Y sobre todo, si además, porque no está aquí en la calidad sólo del Embajador que es; está aquí en calidad de amigo, si me lo permite, de persona que yo estimo mucho y admiro; y que nos hayamos encontrado todos aquí, en la Complutense, con mucho más asistencia que lo que yo creía o me temía. Fue porque me vinieron contando unas historias tétricas, absolutamente tétricas, casi frankestenianas. Me preguntaron... Yo no sé si tu quieres ir porque las cosas 
son complicadas... Bueno, uno se enfrenta con toda realidad, con todas las realidades y finalmente la realidad, que parecía tan amenazadora, no ha podido ser más amistosa.

Pues muchas gracias.

${ }^{\mathrm{i}}$ Lapsus y lusitanismos:

*Escuso es lo que claramente emana de la grabación. Seguramente será un pequeño lapsus del conferenciante.

*Tenta. En español tienta.

* Financia no es palabra española ni tampoco portuguesa. La palabra próxima en portugués es finança y en español 'hacienda'. El autor probablemente quería decir poder financiero.

* El verbo banir no existe en español. Significa "excluir, suprimir, proscribir". Es lusitanismo. 